\title{
Bernal Díaz del Castillo: memoria, invención y olvido*
}

\author{
por \\ María del Carmen Martínez Martínez ${ }^{1}$ \\ Universidad de Valladolid
}

Este artículo da a conocer documentos inéditos que esclarecen el debate abierto sobre Bernal Díaz del Castillo. Se demuestra su capacidad para escribir e incluso su actuación como "escribano». Se recogen testimonios de contemporáneos que le atribuyen la autoría de la Historia verdadera. Se recupera el pleito con el fiscal Villalobos, en el que se conservan tres peticiones del conquistador, y la probanza ad perpetuam rei memoriam que hizo en la villa del Espíritu Santo en marzo de 1539, en la que no consta su participación en la expedición de Grijalva.

Palabras Clave: Bernal Díaz del Castillo; Nueva España; Guatemala; siglo XVI; cronistas; conquistadores.

Cómo citar este artículo / Citation: Martínez Martínez, María del Carmen, "Bernal Díaz del Castillo: memoria, invención y olvido", Revista de Indias, LXXVIII/273 (Madrid, 2018): 399-428. https://doi.org/10.3989/revindias.2018.012.

Bernal Díaz del Castillo se consagró con la Historia verdadera de la conquista de la Nueva España ${ }^{2}$. Pese a que en ella criticó la obra de López de Gómara, por estar mal informado y no ser «testigo de ojos», la lectura de ambas pone en evidencia la dependencia de su relato, hasta el punto que He-

* Este trabajo se inscribe en los proyectos Tradición Clásica y Humanista en España e Hispanoamérica: Narrativas no oficiales. Siglos XVI-XVIII (Ref. FFI2012-37448-C04-01) y La herencia Clásica. Descripciones y representaciones del mundo hispánico, Siglos XVI-XIX (Ref. FFI2015-65007-C4-1-P, MINECO/FEDER) financiados por el Ministerio de Economía y Competitividad del Gobierno de España.

Agradezco a Rodrigo Martínez Baracs sus comentarios.

1 carmen@fyl.uva.es, ORCID iD: http://orcid.org/0000-0002-0106-6955.

2 Díaz del Castillo, 1632. de uso y distribución Creative Commons Reconocimiento 4.0 Internacional (CC BY 4.0). 
berhard Straub habla de plagio ${ }^{3}$. Pero, sin duda, la noticia más sorprendente y polémica ha sido la propuesta de Christian Duverger atribuyendo a Cortés su autoría ${ }^{4}$. Su hipótesis ha suscitado más críticas que adhesiones y propiciado la discusión 5 .

Este artículo pretende esclarecer algunos puntos del debate con nuevos documentos que aportan información sobre Bernal Díaz y lo reafirman como autor de la Historia verdadera, recuperan su actuación ante la justicia ordinaria de la villa del Espíritu Santo, proporcionan pistas sobre el manuscrito que envió a España el presidente Villalobos, descubren sus gestiones en el Consejo de las Indias y revelan cómo sus descendientes apelaron interesadamente a sus méritos, en ocasiones más cercanos a los acreditados con testigos en las probanzas de méritos que a los rememorados en su extensa Historia.

\section{EL HILO CONDUCTOR DE UNA VIDA: HUELLAS DOCUMENTALES}

Para reconstruir la biografía de Bernal $^{6}$, además de lo que contó en su Historia, disponemos de documentos de muy diferente carácter, algunos poco conocidos, como los anteriores a 1539. Hasta la fecha, el testimonio documental más temprano de su presencia en la armada de Cortés es la petición que el procurador Francisco Alvarez Chico presentó en el cabildo de Veracruz el 20 de junio de 1519. En ella los integrantes de «la comunidad»-incluido Díaz- apoyaron con sus firmas el nombramiento de Cortés como capitán general y justicia mayor al tiempo que manifestaron su deseo de que el rey le concediese la gobernación ${ }^{7}$. En 1524, pocos meses antes de seguir a Cortés a Honduras, aparece como testigo en el poder que el regimiento de la villa del Espíritu Santo otorgó a Luis Marín como procurador ${ }^{8}$.

Diversos asuntos lo llevaron a la ciudad de México. Allí, en abril de 1532, declaró en sendas informaciones que realizó Juan Méndez de Sotomayor,

3 López de Gómara, 1552. Straub, 1976: 208. Graulich, 1996: 63-95.

4 Duverger, 2012: 111-112 y 152.

5 Las primeras reacciones aparecieron en mayo de 2013 en la revista mexicana Nexos, en el dosier "El misterioso Bernal Díaz". Además: Serés, 2013: 15-61. Bernard et al., 2013. Martínez Baracs, 2013: 28-30. Thomas, 2013: 31-33.

6 Una semblanza en Barbón Rodríguez, 2005: 3-41. Cerwin, 1963. Cunnighan Graham, 1943

7 Martínez Baracs, 2005: 117. Martínez Martínez, 2013: 263-303. El documento se conserva en el Archivo General de Indias, Sevilla (AGI), México, 95, n. ${ }^{\circ}$ 1, fol. 1-10v.

8 Poder del concejo, justicia y regidores de la villa del Espíritu Santo a Luis Marín, Villa del Espíritu Santo, 2 de julio de 1524, AGI, Justicia, 700, n. ${ }^{\circ}$ 5, s. f. 
procurador del cabildo de la villa del Espíritu Santo, provincia de Guazacualco. En ellas, entre otras cuestiones, se preguntó a los testigos sobre el emplazamiento de la villa y su despoblación, la condición de conquistadores de sus vecinos, la pérdida de términos en favor de nuevas poblaciones y la necesidad de servirse de pueblos y repartimientos. Las respuestas de Bernal, que había ayudado en su población con Gonzalo de Sandoval, tratan asuntos como la navegabilidad del río Guazacualco —más caudaloso que el Guadalquivir recordó - sus buenas condiciones para atracar y reparar navíos, la escasez de población indígena o el deseo de los vecinos de despoblar la villa, idea que también rondaba en su cabeza. Si su descripción y apreciaciones sobre el territorio son muy interesantes — «lo ha andado por pies e vistolo por vista de ojos»y y navegado por la red fluvial de la zona hasta Tehuantepec - su declaración cobra un especial relieve al afirmar en ambas informaciones que fue por «escribano de la visitaçión»» ${ }^{9}$ de los pueblos de las villas de Guazacualco y Tabasco en compañía del vicario Benito López y por orden de la Audiencia. No fue un simple amanuense, según se deduce de las indicaciones recibidas:

Y entonçes el mesmo presidente, juntamente con la Real Audiençia me enbiaron provisión a mí y al benefiçiado, ya por mí nonbrado, para ser visitadores generales de dos villas que eran Guaçacualco y Tavasco, y nos enbiaron la instruiçión de qué manera avían de ser nuestras visitas [...]; y tanbién nos enbiaron provisión para hazer la descripçión de las tierras de los pueblos de las dos villas, lo qual visitamos lo mejor que podimos, y les enbiamos traslado de los proçesos y descripçión de las provinçias y relaçión de todo lo que avíamos hecho ${ }^{10}$.

Pese a que en la Historia silenció que actuó como tal, sus palabras confirman que no era iletrado - como afirma Duverger ${ }^{11}$ — y apuntan una actividad como escribano ${ }^{12}$, posible vía de acceso a la información. La escritura no era para él un secreto y la familiaridad con el mundo de la pluma se rastrea en la Historia verdadera ${ }^{13}$. La descripción que hizo de su mano de aquella

9 Información de la villa de Guazacualco ante la Audiencia de México, declaración de Bernal Díaz, México, 4 de abril de 1532, AGI, México, 203, n. ${ }^{\circ}$ 18. Martínez Martínez, 2013: 63 .

10 Díaz del Castillo, 2005: 836, cap. CCXIII. Citamos por la edición de Barbón Rodríguez, 2005.

11 Duverger, 2012: 112-113.

12 Hubo otros tipos de escribanos, además de los escribanos públicos. Véase Bravo Lozano e Hidalgo Nuchera, 1995: 19-22 y 57-58.

13 Díaz del Castillo, 2005: 655, cap. CLXXVIII. En el Manuscrito Guatemala aparece interlineado y tachado lo que se lee en la edición impresa. Díaz del Castillo, 1632: 202v: «hize 
tierra, pobre, cálida y anegadiza, formaba parte del empeño de Sebastián Ramírez de Fuenleal, presidente de la Audiencia ${ }^{14}$. Debió de ser entonces cuando informó al rey de las quejas de Bernal ${ }^{15}$.

Otra nueva referencia sobre el conquistador aparece en el pleito por la libertad de Isabel, india bizcochera en Tehuantepec. En enero de 1538, cuando fue interrogada en México, afirmó haber servido a Castillo — presentado en las preguntas como "Castillo "el Galán"», apodo atribuido a Bernal ${ }^{16}$ - y criado un hijo de Romaní, quienes «le echaron letras de libre» en reconocimiento de sus servicios ${ }^{17}$. Este sobrenombre fue recordado en 1570 por su hijo Diego Díaz del Castillo al situar el origen de sus antepasados en Medina del Campo ${ }^{18}$. La india Isabel declaró esto en vida de Bernal y muchos años antes del envío del manuscrito a España, lo que resta protagonismo a la sugerida interpolación de su primogénito Francisco para crear una ascendencia honorable ${ }^{19}$.

En las décadas siguientes, el perfil biográfico del cronista se enriquece con otros documentos inéditos: la probanza de méritos que hizo en marzo de 1539 en la villa del Espíritu Santo ${ }^{20}$, las peticiones que presentó en el Consejo de las Indias $(1540)^{21}$, la declaración en un pleito de Rodríguez Cabrillo ${ }^{22}$, una

tinta, y en vn cuero de atambor escriuí a Cortés». Prepararla requería saber las fórmulas, ingredientes y proporciones para su elaboración, conocimientos propios de quienes se movían en el mundo de la escritura.

14 León-Portilla, 1969: 20, «La descripción y relación desta tierra y de las personas de los conquistadores y pobladores que en ella hay enviamos a Vuestra Magestad».

15 Díaz del Castillo, 2005: 836, cap. CCXIII. Barbón Rodríguez, 2005: 1022, «me respondió que en la discreçión que imbiava a Su Magestad desta Nueva España hacía memoria de lo sobre dicho para que de allá se proveyese».

16 Díaz del Castillo, 2005: 541, cap. CLX.

17 Pleito del marqués del Valle y Juan Bautista de Alcocer en nombre y como defensor de Isabel, india bizcochera, sobre su libertad, México, 1537-1538, Archivo General de la Nación, México (AGN), Instituciones coloniales, Hospital de Jesús, vol. 544, leg. 300, exp. 108, fol. 13. El enunciado de la pregunta era: «Yten si saben etcétera que la dicha Ysabel yndia a confesado delante muchas personas y delante presidente y oydores que fue esclava del dicho marqués del Valle y quel la dio a un Castillo el Galán, para que le criase un hijo y quel dicho Castillo la avía hecho libre», Ibidem, fol. 10.

18 Reynolds, 1973: 128. El hijo de Bernal se refirió a su abuelo paterno como «Francisco Díez (sic) del Castillo, el Galán, regidor antiguo de la villa de Medina».

19 Duverger, 2012: 218-219.

20 Información ad perpetuam rei memoriam de los méritos de Bernal Díaz, Villa del Espíritu Santo, 29 de marzo de 1539, AGI, Justicia, 1018, n. 2, ramo 2.

21 Peticiones de Bernal Díaz en el Consejo de Indias, Madrid, 1540, AGI, Justicia, 1018, n. ${ }^{\circ} 2$, ramo 2 ,

22 Declaración de Bernal Díaz del Castillo en el pleito de Juan Rodríguez Cabrillo con Francisco de la Cueva, 1542-1568, AGI, Justicia, 286, n. ${ }^{\circ}$ 4, ramo 2, fol. 213-215. 
carta de poder del cabildo de Santiago de Guatemala (1571)23 o la renuncia de su plaza de regidor en favor de su hijo Francisco (1581) ${ }^{24}$.

Los testimonios documentales citados no fueron mencionados por Barbón Rodríguez en su cuidada edición de la Historia verdadera ni han sido considerados en los estudios sobre el cronista. Todos ellos se suman a los conoci$\operatorname{dos}^{25}$. A modo de recordatorio: testimonios en probanzas de méritos de sus compañeros de conquista ${ }^{26}$, cartas de poder $(1538,1542)$, probanza de méritos de México (1539), gestiones antes las autoridades de la Ciudad Real de Chiapa (1542); carta de dote de Teresa Becerra (1544), cartas a Carlos V (1552), Felipe II (1558 y 1567) y a Bartolomé de las Casas (1558), declaración en el juicio de residencia del presidente Ramírez de Quiñones (1559) ${ }^{27}$, testigo en la toma de posesión de la capilla de los Alvarado $(1568)^{28}$, otorgante de una escritura de arrendamiento (1574) ${ }^{29}$ y parte en un pleito sobre tierras $(1580)^{30}$. De su actividad como regidor hasta los últimos días de su vida dan fe las actas y cartas del cabildo de Santiago de Guatemala. Los documentos citados, que no pretenden ser un inventario completo, ponen de manifiesto que en los archivos se han conservado documentos variados sobre la trayectoria del conquistador. Es posible que algún día lleguemos a conocer otros, entre ellos el testamento que otorgó cerrado ante Juan de Guevara y que se abrió en la ciudad de Guatemala el 3 de febrero de 1584, día de su muerte ${ }^{31}$.

Por otro lado, más de una docena de documentos a su favor aportan información sobre su vida entre 1540 y 1551 (cédulas, órdenes, licencias, recomendaciones $)^{32}$. También en las peticiones, informaciones y probanzas de sus

${ }^{23}$ Carta de poder del cabildo de Santiago de Guatemala a Gregorio de Polanco y Gaspar Arias de Ávila, procuradores, Guatemala, 9 de enero de 1571, AGI, Justicia, 285, n. ${ }^{\circ} 4$, ramo 2 , fol. $2 \mathrm{v}-5 \mathrm{v}$.

${ }^{24}$ Renuncia de Bernal Díaz del Castillo del oficio de regidor en su hijo Francisco Díaz del Castillo, Santiago de Guatemala, 6 de abril de 1581, AGI, Guatemala, 79, n. ${ }^{\circ} 20 \mathrm{~A}$.

25 Los recapitula Gil, 2012: LXXVII-LXXXVII. También Barbón Rodríguez, 2005: 8151063.

${ }^{26}$ Las menciona entre los documentos que jalonan su trayectoria vital Sáenz de Santa María, 1984: 87-116 y 165-172. Grunberg, 2001: 152.

27 Gil, 2012: LXXXI-LXXXII.

28 Barbón Rodríguez, 2005: 26. Toma de posesión de la capilla de los Alvarado, Ciudad de Guatemala, 10 de enero de 1568, AGI, Patronato, 171, n. ${ }^{\circ}$ 1, ramo 12.

29 Barbón Rodríguez, 2005: 1057-1058. La escritura de arrendamiento fue otorgada por Bernal Díaz del Castillo y su mujer, Teresa Becerra, en Santiago de Guatemala, el 29 de diciembre de 1574

30 Cerwin, 1963: 219.

31 Cortés, 1962: 23-25.

32 Sáenz de Santa María, 1984: 170. Gil, 2012: LXXVII-LXXXV. 
descendientes se recuperan datos de gran interés. A las ya conocidas ${ }^{33}$ hay que sumar la información de su hijo Bartolomé Becerra, clérigo presbítero, en la Audiencia de México en $1593^{34}$, hasta donde sé, no citada en los estudios sobre el cronista, que documenta, con testigos que conocieron a Bernal Díaz, la autoría de la crónica.

Entender a Bernal y su escritura requiere no perder de vista su posición en la ciudad de Guatemala y su deseo de posteridad, acicate de su pluma sabedor de que le sobreviviría. Aunque la queja por la falta de reconocimiento de sus méritos planea en sus peticiones y en las de sus descendientes, algunos de sus contemporáneos afirman que era «un hombre muy honrado de quien se hacía mucho caudal» y que la encomienda que heredó su hijo Francisco le permitía vivir con comodidad ${ }^{35}$. Sus relaciones con escribanos, licenciados y miembros de la Audiencia fueron habituales, selladas en ocasiones con lazos familiares. En Guatemala, en las tertulias con sus vecinos, gustaba recordar las memorables hazañas de los conquistadores ${ }^{36}$. Por motivos diversos, entre ellos «para que quede memoria de mí» ${ }^{37}$, obtener mercedes y que en todo «tiempo houiese memoria de tan gloriosa empresa, haçañas y victoria de la conquista» ${ }^{38}$, la narración oral, en la que no faltó la exageración ${ }^{39}$ y un claro deseo de aparentar, dio paso a la escrita, tarea en la que el antiguo conquistador se sintió cómodo (re)escribiendo.

Bernal Díaz utilizó la escritura como memoria de sus méritos, expresión de su descontento y reivindicación colectiva en la que el «yo» se funde con el «nosotros». Su Historia fue considerada un mérito más que añadir a las acciones de guerra y así lo esgrimieron sus descendientes en sus peticiones y promoción.

33 Francisco Díaz del Castillo, Pedro del Castillo Becerra, Juan Becerra del Castillo, Gerónimo Becerra y Diego Díaz del Castillo.

34 Información de Bartolomé Becerra, México, julio de 1593, AGI, México, 221, n. ${ }^{\circ} 4$.

35 Sobre su situación en Guatemala trata Pinto Soria, 2014: 13-23.

36 Declaración de Alonso Hernández Alaras, calcetero, en la información de Bartolomé Becerra, México, 21 de julio de 1593, AGI, México, 221, n. ${ }^{\circ} 4$, «en presencia del dicho Bernal Díaz y deste testigo los dichos conquistadores tratauan de la conquista desta Nueua España y Guatemala y el dicho Bernal Díaz, como persona que se auía hallado en todas ellas y que auía sido el más antiguo conquistador de todos, daua razón de todo». Beckjord, 2007: 127-162.

37 Díaz del Castillo, 2005: 822, cap. CCXII [B].

38 Información secreta de Ambrosio Díaz del Castillo de los méritos de sus padres y abuelos, Santiago de Guatemala, junio de 1622, AGI, Patronato, 88, n. ${ }^{\circ} 3$, ramo 2 (1).

39 Barbón Rodríguez, 2005: 916. Diego Ramírez, compañero en el cabildo, afirmó en 1579: «Y este testigo muchas vezes a oído dezir al dicho Bernal Díaz del Castillo que como a tal conquistador, los capitanes y gobernadores de la dicha conquista le dieron más indios de repartimiento en más partes y lugares que a otro ningún conquistador». 
Publica voz y fama: Bernal Díaz, AUtor DE «UnA MUy LARGa historia»

La atribución de la Historia verdadera a Cortés, que defiende Duverger, la contradicen las pruebas documentales. Hay testigos de la escritura de Bernal Díaz e incluso conocemos los nombres de algunos de sus declarados lectores. Al testimonio tantas veces citado del oidor Alonso de Zorita ${ }^{40}$ podríamos sumar el desconocido y revelador de Cristóbal Pérez, procurador de la Audiencia de México, quien además señala que Bernal enmendaba a otros escritores, lo que evoca varios pasajes de la Historia en que se expresa la intención de «dezir los borrones de los coronistas» ${ }^{41}$. Sus palabras, además, dan fe de la autoridad concedida a su relación mucho tiempo antes de publicarse:

Este testigo vio en la dicha ciudad de Guatimala hazer al dicho Bernal Díaz del Castillo la corónica de quando se ganó esta tierra e las demás partes que la pregunta dize y vido como el dicho Bernal Díaz del Castillo en muchas partes enmendaua la dicha corónica de otras personas que la auían compuesto diçiendo que aquello que él escriuía en el descubrimiento de las partes que la pregunta dize hera verdad porque lo auía él uisto por vista de ojos y ayudado a ganar; y que lo demás que otros escritores auían escrito, mucha parte dello no hera ansí porque hablauan de oídas y él hablaua de uista de ojos porque lo auía ayudado a ganar e conquistar y algunas personas antiguas conquistadores dezían que el dicho Bernal Díaz dezía uerdad porque así auía pasado como él lo dezía y como a tal conquistador le respetauan y honrrauan ${ }^{42}$.

En idéntico sentido se pronunció Gerónimo de Cárcamo, catedrático de Decreto del Estudio mexicano y lector de la curiosa y «muy larga historia» que:

El dicho Bernal Díaz del Castillo, como hombre que se auía hallado en todos los riesgos y recuentros ( $\mathrm{sic}$ ) de la conquista, teniendo cuidado particular de hazer memoria de cada uno dellos, los tenía escritos y hecha una muy larga historia de todo lo que pasó en un discurso tan largo e vario de la conquista desta tierra; la qual historia, por cosa curiosa y digna de ser vista, este testigo leyó desde el principio hasta el cauo ${ }^{43}$.

40 Sáenz de Santa María, 1984: 26-27.

41 Díaz del Castillo, 2005: 47, cap. XVIII.

42 Declaración de Cristóbal Pérez, procurador de la Audiencia, en la información de Bartolomé Becerra, México, 21 de julio de 1593, AGI, México, 221, n. ${ }^{\circ} 4$. Véase Díaz del Castillo, 2005: 44, cap. XVII; Ibidem: 817, cap. CXII [A].

43 Declaración del doctor Gerónimo de Cárcamo en la información de Bartolomé Becerra, México, 3 de agosto de 1593, AGI, México, 221, n. ${ }^{\circ} 4$. Cárcamo era hijo del licenciado 
En Santiago de Guatemala Bernal Díaz era (re)conocido como conquistador y la autoridad otorgada al texto no se discutía por su condición de testigo: «tiene libro escrito della como persona que se halló en todo» ${ }^{44}$. El clérigo Pedro López de Ayala, quien lo conoció como regidor de Santiago, resumió aquella fama, pues «lo oyó dezir en la dicha çiudad de Guatemala a muchas personas antiguas y como tal primero conquistador hizo una corónica desta Nueua España y prouinçia de Guatemala de la conquista dellas y este testigo uido la dicha corónica» ${ }^{45}$. Su testimonio se suma al de otras personas de muy diferente condición que la leyeron, vieron o supieron de su existencia ${ }^{46}$.

La larga y prolija relación resultó interesante a sus contemporáneos, algunos aludidos indirectamente en la Historia verdadera. En ella aparecen curiosos caballeros que se maravillan de su memoria, le preguntan por la ausencia de prólogo y expresan sus críticas al devolverle la copia del manuscrito prestado. Del anonimato rescató a Juan de Guzmán, persona de calidad en Santiago ${ }^{47}$. En las informaciones que promovieron sus descendientes se recuperan otros lectores como Luis Aceituno ${ }^{48}$, Alonso Núñez ${ }^{49}$, Juan de Guevara ${ }^{50}$, Juan Rodríguez Cabrillo de Medrano ${ }^{51}$, fray García de Loaysa, catedrático de la universidad de Guatemala y provincial del convento de Nuestra Señora de la

Bernabé Valdés de Cárcamo, oidor en Guatemala y luego en México, y hermano de Isabel de Cárcamo Valdés, segunda mujer de Francisco Díaz del Castillo.

44 Declaración de Alonso Farfán en la información de Gerónimo Becerra, Guatemala, 1607, AGI, Guatemala, 118, n. ${ }^{\circ} 1$.

45 Declaración de Pedro López de Ayala en la información de Bartolomé Becerra, México, 7 de agosto de 1593, AGI, México, 221, n. ${ }^{\circ} 4$.

46 Barbón Rodríguez, 2005: 57-58, 896 y 937.

47 Díaz del Castillo, 2005: 828, cap. CCXII bis. Tuvo que leer el manuscrito antes de su regreso a la Península, del que informa una Carta del cabildo de Guatemala al rey, Guatemala, 30 de octubre de 1570, AGI, Guatemala, 41, n. ${ }^{\circ} 44$.

48 Barbón Rodríguez, 2005: 972: «leyó y pasó una istoria y corónica que el dicho Bernal Díaz del Castillo escribió de toda la conquista de la Nueba España». Por su condición de escribano y el uso de la expresión «pasó», tal vez colaboró en el traslado del manuscrito.

49 Ibidem: 866: «fue público que avía hecho una istoria de lo que los capitanes avían hecho, la qual este testigo a leído».

50 Declaración de Juan de Guevara en la información secreta de Pedro del Castillo Becerra, Santiago de Guatemala, 23 de enero de 1598, AGI, Guatemala, 115, n. ${ }^{\circ}$ 39: "Bernal Díaz hiço una corónica del descubrimiento e conquista e pacificaçión de la Nueba España y este testigo la a leydo».

51 Sáenz de Santa María, 1984: 27. Barbón Rodríguez: 2005: 56: «una corónica que el dicho Bernal Díaz del Castillo a scripto y conpuesto, de la conquista de toda la Nueva España, que envió a Su Magestad el rey don Felipe, nuestro señor, la qual este testigo a visto y leído». 
Merced $^{52}$, y Francisco Móxica de Vargas, vicerrector del seminario de Nuestra Señora de la Asunción ${ }^{53}$.

En abril de 1581 Bernal Díaz, alegando «soy biejo», hizo dejación condicionada del oficio de regidor de Santiago en favor de su hijo mayor. Poco tiempo después de su muerte, cuando Francisco pidió la confirmación del regimiento, alegó como mérito paterno la crónica que seis años atrás había enviado a la corte el doctor Pedro de Villalobos, presidente de la Audiencia. En la solicitud no dudó en equiparar sus servicios en la guerra con los prestados con la pluma e incluyó una breve descripción del manuscrito que, pese a las gestiones realizadas, no se encontraba en su poder, con el inconveniente que suponía para sus intereses, entre ellos la impresión:

Mi padre fue uno de los primeros descubridores y conquistadores de la Nueva España [...]. Vuestra Alteça le enpeçó a haçer merçed dándole una encomienda de yndios y un regimiento en la dicha ciudad de Guatimala con que no se satisfiço a los muchos seruiçios del dicho mi padre entre los quales es de mucha consideraçión una corónica que hiço con relación verdadera de todo lo subcedido en la conquista de la Nueua España qu'es de más de ducientos y cinquenta pliegos de marca mayor, de letra muy metida, en que gastó mucho tiempo y pasó mucho trauaxo por hauer de pelear y acudir a las neçesidades de la guerra y después al trauaxo de la pluma con el qual, quando no uviera mereçido en la guerra lo ques notorio, hauía hecho notable seruiçio a Vuestra Alteza digno de muy gran remuneraçión; la qual corónica ymbió a vuestro Consejo de las Indias el doctor Villalouos, presidente que fue en la dicha çiudad y audiencia de Guatemala, $<y>$ no la he podido allar, de que soy muy agrauiado ansí por la merçed que pretendo Vuestra Alteça me aga como por el ynterese que de su ynpresión se me podía seguir y porqu'el dicho mi padre ha dos años y medio que murió y dos años antes hauía renunciado su regimiento en manos de Vuestra Alteza ${ }^{54}$.

Bernal Díaz no aclaró en qué momento comenzó a escribir sobre los hechos de los que pasaron con Cortés, ni las circunstancias en las que lo hizo. Por ello las palabras de su hijo resultan llamativas al hacer coetánea la escritura y la guerra «por hauer de pelear y acudir a las neçesidades de la guerra y después al trauaxo de la pluma» ${ }^{55}$. Puede ser una afirmación interesada, o

52 Barbón Rodríguez, 2005: 58: «Bernal Díaz, dice, escrivió la istoria de la dicha conquista, la qual este testigo a leído».

53 Información secreta de Ambrosio Díez del Castillo, Guatemala, 11 de agosto de 1622, AGI, Patronato, 88, n. ${ }^{\circ}$, ramo 2 (1), fol. 31v: «a uisto este testigo y leýdo la Historia de la conquista que escriuió el dicho Bernar (sic) Díaz».

54 Petición de Francisco Díaz del Castillo de la confirmación de la plaza de regidor del cabildo de Santiago [1586], AGI, Guatemala, 79, n. ${ }^{\circ} 20$. El énfasis en la cita es mío.

55 Idem. Díaz del Castillo, 2005: 798, cap. CCVI, aclara su intención «desde que començé azer mi relaçión no fue sino para escrevir nuestros eroicos echos e azañas de los que pasamos con Cortés». 
que solo tomase notas o actuase como escribiente. Habitualmente se considera que inició la redacción a su regreso a Guatemala en 1551, e incluso tal vez antes, cuando fue desprovisto de los pueblos encomendados ${ }^{56}$. Es conocido que en 1563, en la información de Francisco de la Cueva, afirmó tener escrito un memorial de guerras. El hijo de Bernal utilizó el término «verdadera» para calificar la «Historia», para destacar su valor frente a las precedentes.

Los comentarios de Francisco Díaz - más de doscientos cincuenta pliegos de marca mayor y de letra muy metida (apretada) ${ }^{57}$ — son de gran valor por ser la primera descripción del manuscrito que el presidente Villalobos envió a España en 1575. El libro llegó al Consejo de Indias, se acusó recibo de su recepción y acabó en la cámara del rey ${ }^{58}$, donde lo sitúa el cronista Antonio de Herrera cuando lo utilizó para la redacción de la Historia general de los hechos de los castellanos ${ }^{59}$. Barbón hace a Ramírez de Prado propietario del manuscrito ${ }^{60}$ porque León Pinelo señala que la copia corregida para su impresión, el conocido como Manuscrito Remón, fue «sacada del original» que vio en poder del consejero de Indias ${ }^{61}$.

La afirmación de Francisco Díaz coincide con el proceder de Teresa Becerra, viuda del conquistador, para recuperar el manuscrito «que le pidió original» el presidente Villalobos para enviar a España ${ }^{62}$. Varios testigos sitúan

56 Sáenz de Santa María, 1984: 99. Serés, 2011: 1123. Mund, 2001: 21-22.

57 Sobre los textos conocidos de la Historia verdadera véase Barbón Rodríguez, 2005: 43-66. El Manuscrito Guatemala tiene 296 folios y el Manuscrito Alegría 324 folios de texto y seis de índices.

58 Barbón Rodríguez, 2005: 1060.

59 Alegaciones de Antonio de Herrera en sus diferencias con el conde de Puñonrostro (1601), AGI, Patronato, 170, ramo 19. Herrera remite a los folios del libro de mano que utilizó: «Bernal Díaz del Castillo, fol. 4, que le mató por sospechas». En el Manuscrito Guatemala la cita aparece el fol. 2r y en el Manuscrito Alegría en un folio que carece de numeración pero hace el número tres.

60 Barbón Rodríguez, 2005: 61.

${ }^{61}$ León Pinelo, 1629: 75. Asentó «Historia de la conquista de Nueva España M.s. i gran volumen que se halla en esta corte, donde el M. F. Alonso Remón la tiene corregida para imprimir, i es de 300 pliegos, sacada de la original que vi en poder de D. Lorenço Ramírez de Prado, del Real Consejo de las Indias». El título que señala León Pinelo coincide con el que figura en la edición impresa en la suma del privilegio de impresión, en la licencia de la Orden mercedaria y en la tasa de los pliegos. Además, el licenciado Murcia de la Llana advirtió en la fe de erratas «Este libro intitulado Historia de la Conquista de Nueua España se corresponde con su original». De ello se infiere que el cotejo se hizo con el manuscrito preparado para la impresión y que luego se incluyó en el título el término de «verdadera».

62 Carta de poder de Teresa Becerra a Álvaro de Lugo, Santiago de Guatemala, 20 de marzo de 1586, la publica Barbón Rodríguez, 2005: 1061-1062. 
años después en manos de sus descendientes un libro manuscrito ${ }^{63}$. El interés que tenía hizo que en 1628 el escribano Rodríguez Ocampo propusiese sin éxito hacer un traslado autorizado que se custodiase en el archivo del cabildo. El texto de Bernal era ya parte de la memoria colectiva e instrumento valioso para conocer los hechos de los antiguos conquistadores.

En el intento del hijo de Bernal por recuperar el texto paterno se ha considerado el origen del conocido como Manuscrito Alegría ${ }^{64}$, heredado por Ambrosio Díez del Castillo, cuyo nombre aparece varias veces en el manuscrito $^{65}$. Este nieto del cronista, inclinado al estudio y las letras, al igual que sus hermanos que ocuparon dignidades eclesiásticas, rememoró los méritos de sus antepasados ${ }^{66}$. Para él, como para otros vecinos de Guatemala ${ }^{67}$, las citas de Antonio de Herrera y fray Juan de Torquemada ${ }^{68}$ eran prueba de reconocimiento, al igual que la edición de la obra. Argumentaba además que, por ser «de tanta autoridad y tan verdadera y de tanto honor para la naçión española», el consejero de Indias Lorenzo Ramírez de Prado se la entregó al maestro fray Alonso Ramón (sic), historiador general de la orden de Nuestra Señora de la Merced, para que la sacase a luz y, después de superar las revisiones y censuras, se imprimió dedicándose a Su Majestad «como más largamente consta del dicho libro» ${ }^{69}$.

Está claro que Ambrosio tenía puntual información de la edición de la historia verdadera. Al igual que su famoso abuelo debía creer que, como se lee en un verso al inicio de una minuta resumiendo méritos personales y de sus antepasados, «La gloria se a de buscar / que la vida / ella tiene su medida», por ello no dudó en afirmar que «fue muy parecido al primer enperador de Roma Julio César, no en la fortuna del Imperio sino en el valor y virtud e iguales en la espada y en la pluma» ${ }^{70}$.

63 El escribano Juan Rodríguez de Ocampo y el calatravo Juan Laso de la Vega. Sáenz de Santa María, 1961: 208-209. Barbón Rodríguez, 2005: 58-59.

64 Barbón Rodríguez, 2005: 64-66.

65 Sáenz de Santa María, 1984: 40-43. Aparece también como Díaz del Castillo.

66 Información secreta de Ambrosio Díez del Castillo, clérigo presbitero, Santiago de Guatemala, junio de 1622, AGI, Patronato, 88, n. ${ }^{\circ} 3$, ramo 2. Minuta de los méritos del doctor Ambrosio Díez del Castillo, s.f., AGI, Indiferente, 247, n. ${ }^{\circ}$ 1, fol. 1v-2r.

67 Barbón Rodríguez, 2005: 869, testimonio de Cristóbal Aceituno de Guzmán.

68 Sáenz de Santa María, 1984: 142-143. Torquemada, 1969: 351.

69 Méritos del doctor Ambrosio Díez del Castillo Valdés [1638], AGI, Indiferente, 192, n. ${ }^{\circ} 235$, fol. $829 \mathrm{v}-830 \mathrm{v}$.

70 Minuta de los méritos de los antepasados de Ambrosio Díaz del Castillo, s.f. AGI, Patronato, 75, n. ${ }^{\circ}$ 3, ramo 1 (7), fol. 1-2. 
Los testimonios señalados, desde la redacción del manuscrito a su impresión, confirman la autoría de Bernal Díaz, asumida sin discusión por sus contemporáneos, al igual que su condición de conquistador de la Nueva España. Cuestión diferente es si, además de sus borradores y memorias, utilizó otras relaciones e hizo suyos méritos ajenos, como así parece, y los recreó por testimonios escritos, orales o tradiciones asumidas que lo llevaron a presentar como «verdadera» una realidad que, apegándonos a los documentos, no siempre lo es. La memoria de sus méritos es un ejemplo, como ratifica la hasta ahora inédita probanza que hizo en marzo de 1539.

«PARA QUE HAGAN FE EN TODO TIEMPO Y LUGAR»: LAS PROBANZAS AD PERPETUAM REI MEMORIAM DE BERNAL DÍAZ

La práctica de acudir ante la justicia ordinaria o a la Audiencia para acreditar los méritos se generalizó entre los conquistadores y pronto los naturales advirtieron sus ventajas. El trámite era muy conveniente pues si desaparecían las personas que podían dar testimonio de los hechos no habría otro modo de probarlos. El procedimiento permitía, a través del interrogatorio, inquirir a los testigos, que respondían si lo habían visto, oído o así lo creían. La información era la mejor garantía de la verdad de los méritos alegados, lo que no significa negar los posibles vicios del sistema. De esta manera proliferaron las probanzas ad perpetuam rei memoriam que, con el decreto judicial de la justicia ordinaria y la fe del escribano ante el que se hacían, serían válidas en todo tiempo y lugar, tanto en juicio como fuera de él ${ }^{71}$.

Bernal Díaz, con el paso del tiempo, aspiró a que su Historia tuviese idéntica consideración pues «siempre a de aver memoria della» ${ }^{72}$. Sin embargo, como veremos, se distanció de la «verdad» probada con testigos en 1539 - primero en México y pocas semanas después en la villa del Espíritu Santo- cuando manifestó su deseo de hacer probanza «açerca de los serviçios que hize a su magestad en el descubrimiento, conquista e paçificación de toda esta Nueva España» ${ }^{73}$.

Es bien conocido que no le gustó que uno de los licenciados que leyó la Historia le recriminase que, para dar crédito a lo escrito, era preciso dar testigos «y no dezir como digo tan secamente: "esto hize" y "tal me acaesçió",

71 Barbón Rodríguez, 2005: 12. Adorno, 1997: 158-160.

72 Díaz del Castillo, 2005: 6, cap. I. Añón, 2013a: 213-245; 2013b: 121-134.

73 Petición de Bernal Díaz al alcalde ordinario de la villa del Espíritu Santo, 29 de marzo de 1539, AGI, Justicia, 1018, n. ${ }^{\circ}$ 2, ramo 2. 
porque yo no soy testigo de mí mismo» ${ }^{74}$. Fue entonces cuando su pluma, animada por la contrariedad, evocó los «testigos» de sus méritos. En aquel ejercicio de memoria recordó las recomendaciones de Cortés y el virrey Mendoza, las «cartas selladas» de Su Majestad y las probanzas «muy bastantes» que presentó en el «Real Consejo de las Indias, en el año de quinientos quarenta ${ }^{75}$. En los documentos emanados de este organismo se alude a «çiertas ynformaçiones signadas de escrivanos» ${ }^{76}$ y su hijo Francisco afirmó que los méritos paternos constaban en «probanzas y papeles»77 e incluso que «de pedimiento de mi padre se hiçieron provanças secretas» ${ }^{78}$. El uso del plural es indicio de que al menos fueron dos las exhibidas por Bernal aprovechando su viaje a España. La localización del pleito que mantuvo en el Consejo de las Indias así lo corrobora ${ }^{79}$.

Una de ellas, formalizada en México el 9 de febrero de 1539, es conoci$\mathrm{da}^{80}$; otra, hasta ahora no mencionada por ninguno de los estudiosos ni editores de Bernal Díaz, la hizo en la villa del Espíritu Santo el 29 de marzo de 1539. De la primera no conocemos el original, solo el traslado incorporado en las informaciones de sus descendientes ${ }^{81}$. En el pleito con el fiscal Villalobos se conserva el original de un traslado autorizado de la segunda que, a petición de Bernal Díaz, hizo el escribano Cristóbal de Heredia, incluyendo la firma del alcalde ordinario antes de entregárselo cerrado y sellado.

La probanza de marzo de 1539 es un eslabón más en la cadena de actuaciones iniciadas por Bernal el mes anterior en la ciudad de México. El siete de febrero presentó una petición ante el virrey Mendoza y los oidores de la Audiencia solicitando que fuesen recibidos los testigos en la información sobre sus servicios en el descubrimiento, conquista y pacificación de la Nueva España. Le señalaron que, como se acostumbraba en aquellos casos, acudiese ante un alcalde ordinario. Así lo hizo cuando dos días más tarde se

74 Díaz del Castillo, 2005: 817, cap. CCXII [A].

75 Ibidem: 818.

76 Barbón Rodríguez, 2005: 816-817.

77 Petición de Francisco Díaz del Castillo para que se le conceda el regimiento de su padre [Santiago de Guatemala, 1586], AGI, Guatemala, 79, n. ${ }^{\circ} 20$.

78 Barbón Rodríguez, 2005: 914.

79 Proceso de Bernal Díaz, vecino de la villa del Espíritu Santo, con el fiscal del Consejo de Indias, sobre ciertos pueblos de indios que le fueron encomendados como descubridor y conquistador, 1540, AGI, Justicia, 1018, n. ${ }^{\circ}$, ramo 2.

80 Además de los traslados conservados en las informaciones de sus descendientes, la base de datos del CIDA recoge otro en el Archivo Nacional de Costa Rica, Guatemala, Colonial, 1-GA.

81 Barbón Rodríguez, 2005: 821-835. Información secreta de Pedro del Castillo Becerra, Santiago de Guatemala, enero de 1598, AGI, Guatemala, 115, n. ${ }^{\circ} 39$. 
personó ante Juan Jaramillo y el escribano Juan de Zaragoza, a quien entregó la petición y el interrogatorio para el examen de testigos. Los elegidos fueron Cristóbal Hernández, Martín Vázquez, Bartolomé de Villanueva, Miguel Sánchez y Luis Marín ${ }^{82}$.

El 20 de febrero, concluida la declaración de los testigos, Bernal presentó al virrey una petición en la que daba cuenta de la pérdida de la encomienda de Teapa que le había depositado Cortés en los términos de Coatzacoalcos, del pueblo de Chamula que le confió Marcos de Aguilar y las estancias que le asignó el tesorero Alonso de Estrada (Gualpitan y Mincapa, que solían ser sujetos a Cimatlán). Previamente, en varias preguntas del interrogatorio había planteado cómo fue desprovisto de su disfrute. No era la primera vez que había manifestado su disgusto por aquella pérdida y reclamaba una compensación. Años atrás se había quejado sin éxito ante el presidente de la segunda Audiencia de México. Bernal solicitó ante el virrey la posesión de los pueblos que le quitaron u otros del mismo provecho. Su respuesta: «que el dicho Bernal Díaz ocurra a Su Magestad del Emperador», no le dejó otra opción que viajar a Castilla. Fue entonces, el último día de febrero, cuando el marqués del Valle firmó una carta reconociendo los servicios prestados e idéntico comportamiento tuvo el virrey ${ }^{83}$. Lo escrito por Bernal sobre esta cuestión revela que equivoca el destinatario y el año de la recomendación de Cortés. Tanto su carta como la del virrey estaban dirigidas al Consejo de Indias, no al rey ${ }^{84}$, como corroboró su hijo Juan Becerra al exhibir el original ${ }^{85}$. Bernal se equivoca en sus recuerdos ${ }^{86} \mathrm{o}$ miente, no será la única vez ${ }^{87}$.

Con las cartas de recomendación y el traslado de la información de méritos realizada en México regresó a la villa del Espíritu Santo, donde era vecino y regidor. Allí solicitó hacer otra probanza ad perpetuam rei memoriam de sus servicios en el descubrimiento, conquista y pacificación «de toda esta Nueva España» para que hiciera fe y fuese prueba en todo tiempo y lugar ${ }^{88}$.

82 Barbón Rodríguez, 2005: 825-835. Sáenz de Santa María, 1984: 90-91.

83 Sáenz de Santa María, 1984: 91-92. Barbón Rodríguez, 2005: 820.

84 Díaz del Castillo, 2005: 817-818, cap. CCXII [A] y 820-821, cap. CCXII [B]. Barbón Rodríguez, 2005: 820.

85 Barbón Rodríguez, 2005: 945: «otra carta misiba del Marqués del Vale escripta al Real Consejo de las Indias [...] lo mismo refiere el virrey don Antonio de Mendoza en otra carta escripta al Real consejo de Su Magestad, que ansimismo presento para que se me buelban originales».

86 Graulich, 1996: 89. Cortínez, 2000: 16.

87 Miralles, 2008.

88 Información de méritos y servicios de Bernal Díaz, villa del Espíritu Santo, 29 de marzo de 1539, AGI, Justicia, 1018, n. ${ }^{\circ} 2$, ramo 2. 
El mes anterior, en la de México, había utilizado la expresión «toda la más parte desta Nueva España». El 29 de marzo de 1539 se personó ante Juan España, alcalde ordinario, y pidió al escribano del cabildo que leyese la petición y un interrogatorio de catorce preguntas, siete menos que en la probanza de México. En él omitió la de trámite sobre el conocimiento que los testigos tenían del interesado. Tal vez no la consideró necesaria pues los presentados eran, al igual que él, miembros del cabildo de la villa del Espíritu Santo, o tal vez porque no lo conocían de tanto tiempo como hubiera convenido para sus intereses.

Los méritos y hechos declarados por Bernal Díaz, sobre los que serían preguntados los testigos, se resumen en que:

1) Pasó desde la isla de Cuba, a su cuenta y riesgo, con Francisco Hernández de Córdoba a descubrir la Nueva España y que en el pueblo de Champotón recibió dos heridas que pusieron en peligro su vida.

2) Desde Cuba «tornó otra bez» con el marqués del Valle cuando la vino a conquistar, pacificar y poblar, sirviendo muy bien en «todas las más de las entradas» que hizo el marqués, como muy buen escudero, sin sueldo de Su Majestad.

3) Fue en compañía de Cortés a la conquista y pacificación de los términos de México, alrededor de la laguna y sus comarcas, sirviendo muy bien como buen escudero y que, cuando Cortés volvió sobre la ciudad para conquistarla, estuvo en la capitanía de Pedro de Alvarado, siendo herido muchas veces, hasta ganar la ciudad «e preso el señor della».

4) Después de conquistada y pacificada México y las provincias comarcanas, siguió al capitán Gonzalo de Sandoval en la conquista, pacificación y población de los puertos de Veracruz y Guazacualco (Coatzacoalco), sirviendo en su compañía muy bien y lealmente todo lo que pudo, lo que sus fuerzas alcanzaban.

5) Luego fue en compañía del capitán Rodrigo Rangel a la conquista de las provincias de Cimatlán y Copilco, sirviendo en todo lo que se ofrecía hasta quedar en paz la mayoría de los pueblos.

6) Participó luego con el capitán Luis Marín en la conquista y pacificación de las provincias de Chiapa, Zinacantán, Chamula, Guegüeistán (Güeguistlan) y las sierras de Cachula, hallando en la ciudad de Chiapa, estando aún de guerra, cierto oro en joyas del que se pagó el quinto al rey y ciertos caballos que se perdieron en las guerras y entradas. 
7) Después de la conquista de Chiapa acompañó a Hernán Cortés a Honduras, empresa en la que pasó hambre y grandes trabajos, fue por la Mar del Norte y regresó al cabo de dos años por la Mar del Sur, adeudado, desnudo y sin provecho, perdiendo un caballo de guerra en Zulaco que nunca le pagaron.

8) De regreso a la villa de Guazacualco ayudó en la pacificación de los pueblos alzados en la provincia de Xaltebeque, sierras de Cachula, Copilco y otros lugares, sirviendo muy bien y pasando muchos trabajos.

9) En todas las guerras y entradas en la Nueva España sirvió a Su Majestad para que le hiciese mercedes y no por sueldo, soldada ni partido que le hubiesen dado.

10) Es persona muy honrada y como tal ha sido y es regidor de la villa del Espíritu Santo y ha actuado como procurador de la villa ante la Audiencia cumpliendo con lo encargado.

11) Por sus servicios y méritos los gobernadores de la Nueva España (Hernán Cortés, Marcos de Aguilar, Alonso de Estrada) depositaron en él los pueblos de Teapa, Chamula y los poblezuelos de Gualpitan y Mincapa, que poseyó y de los que se sirvió sin contradicción.

12) Le tomaron sus pueblos por fuerza, sin ser oído ni vencido, para la población de las villas de Chiapa y Tabasco, y que no puede sustentarse ni mantener a dos hijas.

13) Solicitó muchas veces sus pueblos en la ciudad de México ante el obispo de Santo Domingo y el virrey, que informaron al emperador de su situación, sin recibir recompensa alguna por su pérdida.

14) Todo lo dicho era público y notorio.

El mismo día de la presentación del interrogatorio juraron como testigos el alcalde ordinario Julián Pardo y el regidor Gonzalo Hernández, al igual que Díaz conquistadores de México. Meses después, el 6 de mayo, lo hizo Pedro Tostado ${ }^{89}$. Resulta llamativo que de «toda la flor» ${ }^{90}$ de los caballeros y soldados que habían poblado la villa del Espíritu Santo, solo presente a tres vecinos que, si bien respondieron a todas las preguntas, en ninguna de sus respuestas significaron sus actuaciones y, además, declararon de oídas a las dos primeras.

La reducción del número de preguntas y de testigos pudiera estar relacionada con la situación económica de Bernal Díaz y la despoblación de la villa. Los derechos del escribano se incrementaban en función del número de tes-

\footnotetext{
89 Grunberg, 2001: 235, 404 y 540.

90 Díaz del Castillo, 2005: 543, cap. CLX.
} 
tigos a los que tomaba declaración y las planas de papel que rellenaba con las respuestas. Por otro lado, sorprende la escasa huella de los testigos de la probanza en la Historia verdadera, sobre todo si tenemos en cuenta que el Pardo $^{91}$ registrado responde al nombre de Bartolomé, que Gonzalo Hernán$\mathrm{dez}^{92}$ solo es mencionado al hilo de un enfrentamiento con el factor Salazar y que de Pedro Tostado solo recordó que pasó con un hermano del que omitió el nombre de pila ${ }^{93}$.

Considerando ambas probanzas y las respuestas de los testigos es posible confirmar la narración de algunos capítulos de la Historia verdadera, reafirmar las sospechas sobre otros pasajes y encontrar circunstancias que silenció por alguna razón. Nos detendremos en su participación en la expedición de Grijalva $^{94}$, en la novedosa presentación de su persona como «escudero», la posesión de caballo y en el oro que encontró en Chiapa.

Bernal no planteó como mérito en ninguna de las probanzas conocidas la presencia en la expedición de Grijalva. En ambas afirma que, después de la de Hernández de Córdoba, regresó con Cortés. La doble omisión refuerza la idea de que no participó y que con el paso del tiempo hizo suyo el mérito, cuestión sobre la que llamó la atención Henry Wagner ${ }^{95}$. Lo cierto es que después de escribirlo no dudó en afirmarlo cuando se presentó la ocasión, incluso bajo juramento, remitiéndose a su crónica ${ }^{96}$.

La falta de concordancia entre las probanzas de 1539 y lo escrito en la Historia verdadera se comprueba en varios testimonios. En los márgenes de una plana del Manuscrito Alegría se hicieron llamadas de atención repitiendo «ojo» en los renglones de las expediciones de Hernández de Córdoba, Grijalva y Cortés ${ }^{97}$. Hay que notar que no todos sus descendientes hicieron coro en situarlo en las tres expediciones. Si bien Francisco ${ }^{98}$ y Diego Díaz siguieron el guión del relato paterno ${ }^{99}$, no lo hicieron sus hermanos Bartolomé Bece-

\footnotetext{
91 Ibidem: 42, cap. XVI y 783 cap. CCV.

92 Ibidem: 682, cap. CLXXXV.

93 Ibidem: 792, cap. CCV.

94 Ibidem: 817, cap. CCXII [A]. La expedición de Grijalva en cap. VIII a XVII.

95 Wagner, 1945: 159. Grunberg, 2001: 150-153.

96 Díaz del Castillo, 2005: 7, cap. I. Barbón Rodríguez, 2005: 1001: «se halló en la conquista y descubrimiento de la Nueba España y otras partes, dos bezes antes que el dicho Hernando Cortés, tiene escrita una corónica y relazión, a la qual también se remite».

97 Códice Alegría, Biblioteca Nacional de España, Madrid (BNE), Vitr/26/12, fol. 2v.

98 Barbón Rodríguez, 2005: 836.

99 Información de Diego Díaz del Castillo, México, 1618, AGI, Patronato, 87, n. ${ }^{2}$, ramo 1 .
} 
rra $^{100}$, Juan Becerra ${ }^{101}$ y Pedro del Castillo ${ }^{102}$, que se ciñen a las probanzas de 1539. La secuencia también queda expresada con total claridad en los papeles de su nieto Tomás Díaz del Castillo, en los que se lee que Bernal fue:

Uno de los primeros descubridores, conquistadores y pobladores del rreyno de la Nueua España, Chiapa, Yucatán y estas probincias de Guatemala y de las Higueras en compañía del capitán Francisco Hernández de Córdoua, que fue el primero descubridor, en que padeció muy gran trauaxo principalmente en la entrada del pueblo de Chanpotón en la Nueba España, y segunda vez boluió y continuó la dicha conquista con don Fernando Cortéz, marquéz del Valle ${ }^{103}$.

Lo mismo que había afirmado Bernal Díaz en su petición al virrey, lo que probó en sus informaciones y lo que repitió en la corte, lugar en el que de haber sido cierta la participación en la expedición de Grijalva no lo hubiera silenciado en defensa de sus intereses. Se limitó a señalar que fue «uno de los primeros que fueron en el descubrimiento e conquista de la dicha Nueva España ${ }^{104}$, lo que acreditaban sus probanzas.

La falta de correspondencia entre las informaciones y lo dicho en la $\mathrm{His}$ toria la sortearon en este punto como pudieron algunos nietos de Bernal. Así aparecen unidos los apellidos de ambos capitanes, como si se tratase de una sola persona. Ambrosio Díaz del Castillo en una relación de sus méritos afirmó que su abuelo: «vino antes del marqués del Valle a descubrirlas en compañía de los capitanes Francisco Hernándes Grijalva» ${ }^{105}$. Situación similar se advierte en una relación de los méritos de Pedro de Cárcamo Valdés en la que se lee que Díaz pasó «en compañía de el capitán Francisco Hernández de Grijalva y después de esto bolvió con el dicho marqués a la conquista» ${ }^{106}$. En

100 Información de Bartolomé Becerra (tercera pregunta), México, 12 de julio de 1593, AGI, México, 221, n. ${ }^{\circ}$ 4: «auer venido con el capitán Francisco Hernández Grijalua antes que viniese el marqués del Valle a esta Nueua España y después vino con el dicho marqués».

101 Petición de Juan Becerra del Castillo, Santiago de Guatemala, 5 de enero de 1601, AGI, Guatemala, 120, n. ${ }^{\circ}$ 1(2), fol. 12r: «después de auerla descubierto volvió con don Fernando Cortés». Las informaciones que hizo en 1600 y 1605 en Barbón Rodríguez, 2005: 943-982.

102 Barbón Rodríguez, 2005: 859.

103 Nombramiento de Tomás Díaz del Castillo como beneficiado de San Francisco Zapotitlan, Guatemala, 18 de septiembre de 1625, AGI, Patronato, 75, n. ${ }^{\circ} 3$, ramo 1 (4), fol. 29.

104 Petición de Bernal Díaz en el Consejo de Indias, Madrid, abril de 1540, AGI, Justicia, 1018, n. $^{\circ} 2$, ramo 2, fol. 1 .

105 Méritos de Ambrosio Díaz del Castillo Valdés, [1638], AGI, Indiferente, 192, n. ${ }^{\circ} 235$, fols. $829 \mathrm{v}-830 \mathrm{v}$.

106 Méritos de Pedro de Cárcamo Valdés, Guatemala, 8 de abril de 1642, AGI, Indiferente, 192, n. $^{\circ} 128$, fol. 306v. En su versión impresa una mano interlineó los nombres de ambos 
la de Tomás Díaz del Castillo, el provincial general del convento de la Merced de la ciudad de Guatemala declaró haber oído a sus mayores que Bernal Díaz pasó «dos veces», primero con Grijalva y luego con Cortés ${ }^{107}$.

Volviendo a la información de marzo de 1539, ninguno de los testigos presentados en la villa del Espíritu Santo puede acreditar «con muy cierta verdad como testigo de vista» la presencia de Bernal Díaz en las expediciones de Hernández de Córdoba y Cortés. Todos lo han oído decir. A aquella fama, aunque fuese de oídas, sumó la participación en la de Grijalva que se convirtió, en boca del antiguo y conocido conquistador, en pública voz y fama. Así parece que lo había asumido ya en 1557, cuando declaró en la probanza de Francisco de la Cueva ${ }^{108}$. Amparado en su reputación sucumbió a la tentación de incluir este mérito en su Historia y en su memoria, sin contradicción, remitiendo a su lectura ${ }^{109}$. Pero en su decisión era cautivo del carácter perdurable de la letra escrita y del procedimiento de las probanzas ante escribano, cuando libremente seleccionó los hechos «dignos de saber y no poner en el olvido». Aquellas «informaciones auténticas» ${ }^{110}$, con todos los requisitos formales y legales, eran memoria perpetua de sus méritos, las que darían fe en todo tiempo y lugar. En ninguna de ellas aparecía su participación en la expedición de Grijalva que incluyó insistentemente en la Historia verdadera siguiendo probablemente el relato de Fernández de Oviedo ${ }^{111}$ y la información que circulaba entre los conquistadores.

La reiteración de su condición de escudero en tres preguntas (II, III y VI) de la probanza del Espíritu Santo resulta llamativa por la ausencia del término en la de México y en la Historia verdadera, en la que encontramos «ca-

capitanes, remitiendo en la corrección a la "Memoria de las batallas y encuentros" de la edición de la Historia verdadera (cap. CCXII). Relación impresa de los méritos de Pedro de Cárcamo Valdés, 1644, AGI, Indiferente, 247, n. ${ }^{\circ}$ 2, fol. 4r: «y en ella dize a foxas 253 y 254, refiriendo por menor los descubrimientos, conquistas, batallas y renquentros de guerra en que se alló y en Cuba, Yucatán, Florida, Tabasco, Tlaxcala, Cholula, Méjico [...] que fueron todas 119 batallas y renquentros de guerra y en las batallas en que sirvió».

107 Declaración del mercedario fray García de Loaysa en la información de Tomás Díaz del Castillo, Guatemala, 11 de mayo de 1629, AGI, Patronato, 75, n. ${ }^{\circ} 3$, ramo 1 (3), fol. 2930: «que pasó dos vezes, primero con Grixalva y, no teniendo efeto la conquista, volvió segunda vez en conpañía de don Fernando Cortés, marqués del Valle, en cuya compañía sirvió a la corona de Castilla».

108 Barbón Rodríguez, 2005: 986.

109 Ibidem: 1001. Así lo hizo en diciembre de 1569 en la probanza de Francisco de la Cueva.

110 Ibidem: 862: Declaración de Pedro Navarro, relator de la Audiencia, en la información de Pedro del Castillo, Santiago de Guatemala, 16 de abril de 1613.

111 Barbón Rodríguez, 2005: 13. 
balleros», «hidalgos», «ballesteros», «espingarderos», «escopeteros», «rodeleros», «pajes de lança», «soldados», etc., que traducen jerarquía, posiciones sociales y actividades en la hueste. Curiosamente el término se sustituyó por «muy buen caballero» en la información de su hijo Francisco Díaz, pasó a «muy leal vasallo» en la de Pedro del Castillo ${ }^{112}$, y en la memoria colectiva a «muy buen soldado» ${ }^{113}$, pues como él mismo recordó «todos me tenían a mí en reputaçión de buen soldado» ${ }^{114}$. Pero el término escudero no desapareció del léxico de Bernal ${ }^{115}$ quien en su crónica se atribuyó el papel de alférez y capitán ${ }^{116}$.

Duverger considera que Francisco Díaz retocó la Historia verdadera para apropiarse de la obra. Así le atribuye la referencia de que Bernal tuvo caba$1 \operatorname{los}^{117}$. Sin embargo, en las dos probanzas de 1539 incluyó como servicio la pérdida de un caballo de guerra en Zulaco, durante la expedición a las Hibueras, según cuenta en la Historia, si bien con el paso de los años triplicó su valor ${ }^{118}$. Uno de los testigos de la información que hizo en México, Bartolomé de Villanueva, recordó que celebraron la jornada, pues saciaron el hambre ${ }^{119}$. Julián Pardo, que declaró en la del Espíritu Santo, «vio que se le murió» en una entrada. Si en los momentos iniciales de la conquista no contó con cabalgadura, con el paso del tiempo la adquirió.

Omisión curiosa en la Historia verdadera es el hallazgo en la ciudad de Chiapa de «çierto oro en joyas de que se pagó el quinto a su Majestad» y que sirvió para compensar las cabalgaduras perdidas en las entradas. Este mérito también lo adujo en la probanza de México y fue recordado por doña Jacoba de Orozco quien, en un memorial en 1629, lo sitúa en la sierra de Cachula ${ }^{120}$. En la información de marzo en la villa del Espíritu Santo el hallazgo fue confirmado por el regidor Gonzalo Hernández por habérselo oído a Pedro

\footnotetext{
112 Ibidem: 872.

113 Ibidem: 898: Declaración de Francisco Hernández de Illescas, Santiago de Guatemala, 12 de febrero de 1608 .

114 Díaz del Castillo, 2005: 7, cap. I: «sienpre tube çelo de buen soldado» y 801, cap. CCVII.

115 Declaración de Bernal Díaz del Castillo en la información de Alonso Martín Calagraño, Santiago de Guatemala, 22 de octubre de 1567, AGI, Patronato, 68, n. ${ }^{\circ}$ 1, ramo 1, s. f. Al responder a la pregunta catorce lo calificó de «buen escudero, todo con mucha honrra y buen soldado».

116 Miralles, 2008: 299.

117 Duverger, 2012: 218-219.

118 Lo recordó expresamente en la memoria de batallas en las que participó. Díaz del Castillo, 2005: 825, cap. CCXII [B] y 649, cap. CLXXVII.

119 Barbón Rodríguez, 2005: 829.

120 Ibidem: 875-876. Gil, 2012: XXXIII.
} 
Tostado, Julián Pardo y al capitán Luis Marín, quien lo corroboró en la probanza de México. La «prodigiosa» memoria de Bernal lo omitió de forma interesada $^{121}$. Puede que con el silencio resaltase la penuria denunciada y los méritos no reconocidos ni premiados.

Las preguntas y respuestas de ambas probanzas muestran hasta qué punto Bernal rememoró en la Historia verdadera una realidad bien diferente a la que probó con testigos y ante escribano mucho tiempo antes de que la lectura de la Historia de la Indias de López de Gómara lo llevase a señalar sus borrones. Es conveniente recordar que dijo «ençalçan a unos capitanes y abaxan a otros, y los que no se hallaron en las conquistas dizen que fueron en ellas» ${ }^{122}$. ¿Tropezó en la misma piedra al narrar su participación en la expedición de Grijalva? Así lo apuntan las fuentes documentales, lo que una vez más lleva a reflexionar sobre la credibilidad otorgada a su obra y su autoridad histórica.

Sin Reposo ni Sosiego: De la Audiencia de MéXico al Consejo DE INDIAS

Pocos años después de establecerse la villa del Espíritu Santo se poblaron las de Santa María de la Victoria, Chiapa y Sant Alifonso con muchos pueblos de los que se servía la primera. Pese a que en la Audiencia de Nueva España hubo pleito de la villa del Espíritu Santo con las de Chiapa y Tabasco por los términos que le tomaron, poco pudo argumentar en su derecho Bernal, que se apartó alegando que el despojo lo dejó sin recursos ${ }^{123}$. Decía vivir sin reposo ni sosiego por no tener los pueblos que le quitaron; de nada sirvió presentar sus quejas al presidente Ramírez de Fuenleal y luego al virrey Mendoza, que poco podían hacer en su favor, por ello viajó a la corte con el deseo de ser recompensado con alguna merced.

Bernal Díaz recordó el viaje a Castilla, su paso por los estrados del Consejo de Indias y el luto que entonces guardó por la muerte de la emperatriz ${ }^{124}$. A los negocios que ocuparon su tiempo se alude en las cédulas que obtuvo para el virrey de la Nueva España y Pedro de Alvarado, pero nada concretó en su Historia. Hasta la fecha no conocíamos otro indicio documental del contradictorio juicio que mantuvo con el fiscal Villalobos. En el proceso, que

121 Díaz del Castillo, 2005: 577, cap. CLXVI.

122 Ibidem: 46, cap. XVIII.

123 Ibidem: 543-544, cap. CLX.

124 Ibidem: 759-760, cap. CCI. 
se ha conservado incompleto, además de la información de méritos de marzo de 1539 hay tres peticiones inéditas de Bernal Díaz ${ }^{125}$. Una de ellas, dirigida al rey, parece obra de su mano ${ }^{126}$, en otra firmó y en la tercera se anotaron en el margen izquierdo las decisiones del Consejo sobre sus peticiones.

Dispuesto a resolver la pérdida de sus encomiendas, en abril de 1540 presentó en el Consejo de Indias una petición reclamando los pueblos de indios que le quitaron para la población de las villas de Santa María de la Victoria y Chiapa. Apelando a sus méritos en el descubrimiento y la conquista de la Nueva España, donde sirvió «como buen escudero», solicitó que se le diese «otra cosa yquivalente a lo que se le tomó»" ${ }^{127}$.

En aquellos momentos Hernán Cortés y algunos de sus compañeros de conquista como Andrés de Tapia, Jorge de Alvarado y Diego Colio no habían alcanzado la corte. El marqués había zarpado de Veracruz a comienzos de enero y entró en Madrid a mediados de mayo ${ }^{128}$, cuando Bernal Díaz ya había iniciado el proceso en el Consejo de Indias, lo que prueba que no viajaron juntos, aunque coincidieron en la corte. Desconocemos si alguno de ellos intervino en su favor, circunstancia que, si se dio, no ha dejado huella alguna o no hemos dado con ella.

En su pretensión Bernal no dudó en mencionar casos similares, como los de Francisco Marmolejo, Miguel Sánchez Gascón y Gonzalo Hernández, también vecinos de la villa del Espíritu Santo, que vieron satisfechas sus peticiones. Era consciente de que el remedio no era posible en la Nueva España, por no haber indios que encomendar, como tampoco lo era quitar a las nuevas villas los indios de los que se había servido pacíficamente hasta que le fueron arrebatados. Su deseo de regresar a las Indias «para siempre servir a vuestra magestad como siempre ha fecho e casar sus hijas» hizo que obrase con inteligencia y que reaccionase con rapidez ante las decisiones del Consejo de Indias buscando todo tipo de seguridades.

$\mathrm{Su}$ petición fue vista por el licenciado Villalobos, fiscal del Consejo de Indias. La respuesta fue desaconsejar la merced alegando que «ni es tal conquistador ni le fueron encomendados los pueblos por méritos ni por persona

125 Bernal Díaz, vecino de la villa del Espíritu Santo, con el fiscal, sobre ciertos pueblos de indios que le fueron encomendados como descubridor y conquistador, 1540, AGI, Justicia, 1018, n. $^{\circ} 2$, ramo 2.

126 Así parece del examen caligráfico de los folios considerados autógrafos en el Manuscrito Guatemala (fols. 269, 270, 274v, 275 a 278 y 285v) y de las cartas de 1552 y 1558 atribuidas a su pluma. Barbón Rodríguez, 2005: 51.

127 Petición de Bernal Díaz al emperador presentada en el Consejo de Indias, Madrid, abril de 1540, AGI, Justicia, 1018, n. ${ }^{\circ}$ 2, ramo 2, fol. 1.

128 Martínez Martínez, 2015: 579-580. Díaz del Castillo, 2005: 759, cap. CCI. 
que para ello tuviese poder ni tal prueba por probança que baste» ${ }^{129}$. Tal vez lo dedujo de los testimonios de las presentadas. Recordando la del Espíritu Santo, Julián Pardo creía que en la conquista de la ciudad de México y sus alrededores serviría «como persona de bien e como otros lo haçían». Gonzalo Hernández, compañero en la capitanía de Alvarado, hizo el mérito colectivo pues «se pasaron muchos trabajos en la paçificaçión de la dicha çibdad e de las provincias comarcanas». Tampoco ayudaba a su favor el testimonio de Pedro Tostado, pues hizo «lo que podía, como los demás» y en otras entradas y conquistas sirvió «muy bien [...] porque todos los que en ello se hallaron lo hizieron muy bien», «como los otros compañeros» ${ }^{130}$. Afirmaciones similares hicieron los testigos que declararon en la probanza de México.

El 15 de abril de 1540, cuando se notificó a Bernal la decisión del fiscal Villalobos, pese a las duras palabras, negando lo perjudicial para sus intereses, dio el pleito por concluso. Aquel mismo día, el auto pronunciado en el Consejo dispuso el envío de una real cédula para que el virrey de la Nueva España se informase de la calidad y cantidad de los pueblos de los que había sido desprovisto y le asignase otros tan buenos en la misma provincia ${ }^{131}$.

Logrado el objetivo de ser recompensado con otros pueblos del mismo aprovechamiento que los perdidos, trató de allanar futuros problemas en el cumplimiento de lo ordenado al virrey. Las nuevas encomiendas se le darían en la misma provincia que las disfrutadas, pero aquellas se encontraban en la gobernación de otros gobernadores. Además, bien sabía que los indios ya estaban repartidos con lo que se vería obligado a acudir de nuevo ante el rey. Por ello, apelando a su condición de primer descubridor y conquistador, a los servicios prestados y a su deseo de permanecer en la tierra, en la solicitud firmada de su mano, pidió que se ordenase al virrey que la recompensa fuese en una de las provincias de Nueva España «que sea más en comarca de la tierra adentro porqu'él entiende casar sus hijas en México o en Guajaca o en Mechuacán» y en indios vacos en cabeza de su Majestad ${ }^{132}$. Sin más mención o detalle, debe referirse a las que dice haber tenido con doña Francisca, joven que le había ofrecido Moctezuma, recordado en la probanza del Espíritu Santo indirectamente con vagas expresiones como "gran cacique» y «preso el

129 Respuesta del fiscal Juan de Villalobos a la petición de Bernal Díaz, Madrid, 15 de abril de 1540, AGI, Justicia, 1018, n. ${ }^{\circ}$ 2, ramo 2.

130 Información de méritos y servicios de Bernal Díaz, villa del Espíritu Santo, 29 de marzo de 1539, AGI, Justicia, 1018, n. ${ }^{\circ}$ 2, ramo 2.

131 Auto del Consejo de Indias, Madrid, 15 de abril de 1540, AGI, Justicia, 1018, n. ${ }^{\circ} 2$, ramo 2 .

132 Petición de Bernal Díaz, Madrid, s.d., abril de 1540, AGI, Justicia, 1018, n. ${ }^{\circ}$ 2, ramo 2. 
señor della». Mientras que en la Historia verdadera, al escribir sobre el encuentro con Moctezuma, resaltó «se me representa todo delante de mis ojos, como si ayer fuera quando esto pasó» ${ }^{133}$, en 1539 no da esa sensación. Examinada su petición en el Consejo de Indias, el 17 de abril de 1540 se acordó que si los pueblos no se le podían dar cómodamente, el virrey se los señalase equivalentes en otra parte y sobre ello se ordenó despachar otra cédula ${ }^{134}$.

En el intento de reubicarse en el espacio, en otra petición solicitó que la recompensa de los pueblos se le diese en la provincia de Guatemala. Viendo que lo logrado podría quedarse en nada si cuando regresase el adelantado Alvarado no se encontrase en su gobernación, se apresuró a solicitar que la provisión

... hable con el dicho adelantado o su lugarteniente mandándoles que luego la cumplan so graves penas, no enbargante que los pueblos de yndios que le fueron tomados no estén dentro de su governaçión, porque esta es su merçed y voluntad y que, no cumpliéndolo, mande al presidente e oydores de la Abdiençia de México que enbíen persona a su costa para que se la hagan guardar y cumplir y que los dichos yndios que le oviere de dar sean en Guatimala o en la villa de San Saluador o en sus términos, de los que estuvieren vacos o vacaren ${ }^{135}$.

A estas alturas Bernal busca todo tipo de garantías pues, una vez en las Indias, era consciente de los múltiples juegos que de nuevo lo podrían privar de la merecida recompensa. Sus temores afloran al solicitar una cédula o provisión real para que no se consienta «en las dichas provinçias que se haga ningún trueque de yndios entre unas personas y otras ni se puedan vender ni enajenar ni traspasar ni dar en casamientos porque de otra manera jamás avrá efecto lo que por vuestra magestad está mandado ni se le darían yndios en toda su vida ${ }^{136}$. Sabedor del tiempo que podría pasar hasta disfrutar de las prometidas encomiendas solicitó un buen corregimiento con el que sustentarse él y sus hijas. Así se le concedió ${ }^{137}$.

133 Díaz del Castillo, 2005: 222, cap. CCXIII.

134 Auto del Consejo de Indias, Madrid, 17 de abril de 1540, AGI, Justicia, 1018, n. ${ }^{\circ} 2$, ramo 2. Real cédula al virrey Mendoza, Madrid, 3 de julio de 1540, AGI, Guatemala, 393, L. II, fol. $118 \mathrm{r} / \mathrm{v}$.

135 Petición de Bernal Díaz al Consejo de las Indias, Madrid, s. f., AGI, Justicia, 1018, n. ${ }^{\circ}$, ramo 2, fol. 17. La real cédula a Alvarado y su lugarteniente es de 19 de junio de 1540, la publica Barbón Rodríguez, 2005: 816-817.

136 Petición de Bernal Díaz, Madrid, s. f., AGI, Justicia, 1018, n. ${ }^{\circ}$ 2, ramo 2, fol. 17.

137 Barbón Rodríguez, 2005: 818, Real Cédula al virrey Mendoza, Madrid, 2 de julio de 1540 . 
Un problema añadido era cómo probar la calidad y cantidad de los pueblos que poseía y que le quitaron. Conocedor de la realidad administrativa se adelantó a lo que pudiera pasar porque

... sy él huviese de yr a Guatimala al governador a pedir que cumpla lo que le está mandado y el dicho gobernador oviese de enviar a hazer la ynformaçión a Chiapa y a Tavasco, donde están los dichos pueblos, sería nunca acabar porque está de la dicha governaçión más de çiento y setenta leguas. Suplica a vuestra Magestad mande dar su çédula rreal para los alcaldes y justicias de las dichas villas de Chiapa y Tavasco para que hagan la dicha ynformaçión de lo susodicho y mande al dicho governador o su lugartheniente que, constándole por la dicha ynformaçión, le dé la dicha reconpensa syn enbiar a hazer ynformaçión alguna más de la quel llevare hecha de las dichas justiçias ${ }^{138}$.

La respuesta del Consejo de que los gobernadores de la jurisdicción realizarían la información y tendrían que cumplir lo dispuesto debió de tranquilizarlo. Con aquel convencimiento regresó llevando como un tesoro la carta ejecutoria del pleito que también exhibieron sus descendientes ${ }^{139}$. El 14 de noviembre de 1541 se presentó en Santiago de Guatemala con la cédula para el adelantado Alvarado o su lugarteniente y el auto del Consejo de Indias ${ }^{140}$. En enero del año siguiente otorgó un poder a Juan Pérez de Ardón, Sancho Barahona y Francisco Caba para la atención de sus asuntos. Un mes después solicitó ante la justicia ordinaria de Chiapa hacer información sobre lo que rentaban los pueblos perdidos, primer paso para que se le diesen otros equivalentes ${ }^{141}$. Por ello presentó pruebas para «superabundancia» de sus razones, e insistió personalmente o en su nombre quienes tenían su poder. Finalmente se le concedieron los pueblos de Joanagazapa, Sacatepéquez y Misten. La decisión, después de tanto esfuerzo, no fue de su agrado por considerar que no eran del provecho suficiente para compensar los anteriores y por ello, de nuevo en Castilla, en 1550 insistiría en su petición recordando lo dispuesto una década antes y la carta ejecutoria ganada en $1540^{142}$. El paso del tiempo contribuyó a que el despojo fuese relatado de manera diferente. La versión

138 Petición de Bernal Díaz, Madrid, s.f., AGI, Justicia, 1018, n. ${ }^{\circ}$ 2, ramo 2, fol. 17. En el auto del Consejo de Indias de 15 de abril de 1540 se parafrasea esta petición. Con la diligencia de su presentación en Guatemala lo publicó Barbón Rodríguez, 2005: 1006.

139 Barbón Rodríguez, 2005: 944. A ella aludió Juan Becerra en una petición: «hago presentación ante Vuestra Señoría de esta executoria real pleiteada con el físcal del Real Consejo de las Indias».

140 Ibidem: 1005-1006. El pronunciado el 19 de junio de 1540.

141 Ibidem: 1008-1010.

142 Ibidem: 818-819. 
que circuló en Guatemala, donde llegó con voz de conquistador, era que los indios que le habían dado en Guazacualco «los había dejado y dejó bacos»» ${ }^{143}$.

\section{CONCLUSIONES}

Teniendo en consideración los documentos que se conservan no se puede decir que la vida de Bernal Díaz esté sumida en el anonimato, lo que no impide reconocer que todavía hay lagunas y etapas con más sombras que luces. Felizmente, explorar los archivos puede deparar hallazgos novedosos que, después de ser sometidos a un análisis científico, aportan información sustancial sobre su trayectoria y obra.

La petición al cabildo de Veracruz de 20 de junio de 1519, el primer documento conocido hasta ahora de los españoles en la Nueva España, lo sitúa en la expedición de Cortés y entre los que con su firma apoyaron la petición de la gobernación para el capitán. Además, por boca de Bernal sabemos que sabía escribir, con la suficiente habilidad como para registrar de su mano la visita que hizo a las villas de Guazacualco y Tabasco acompañando al vicario Benito López, comisión imposible si hubiese sido un iletrado. La credibilidad de este testimonio cuenta a su favor con la diligencia del escribano Alonso Lucas y el parecer de la Audiencia en el que expresamente se alude a la descripción de la tierra y figuran las firmas originales del presidente Ramírez de Fuenleal y de los licenciados Salmerón, Maldonado y Ceinos, oidores.

Por otro lado, la probanza que hizo en la villa del Espíritu Santo en marzo de 1539, en la que no incluyó para perpetua memoria la expedición de Grijalva, es una prueba más de que no participó en ella, circunstancia que ratifica el que no lo esgrimiese en las peticiones que presentó en el Consejo de las Indias, sobre todo cuando el fiscal dudó de su condición de conquistador. El testimonio original de esta probanza disipa cualquier duda sembrada sobre los méritos alegados en la de México por el mero hecho de ser una copia dentro de una copia posterior. El hallazgo del pleito con el fiscal Villalobos acredita sus actuaciones para recuperar los pueblos perdidos y prueba documentalmente su presencia en España en 1540.

Pese a las continuas quejas, los hijos de Bernal Díaz se situaron bien, tanto en México como en Guatemala. Los méritos de su padre fueron repetidos en sus peticiones apelando al servicio que hizo con la pluma y a la «verdad» de su Historia. De la mano de su hijo Francisco — que no intervino en el texto de su padre en los pasajes que se le han atribuido- es novedosa la

143 Ibidem: 918. 
temprana descripción del manuscrito enviado a España. Los testimonios inéditos aportados de la información de Bartolomé Becerra (1593) nos acercan a la intención de su escritura y a sus lectores, algunos de gran consideración intelectual en su tiempo, como el doctor Gerónimo de Cárcamo, catedrático de la Universidad de México, quien lo conoció en Santiago de Guatemala.

La narración de Bernal Díaz se distancia en muchos pasajes de lo que podemos contrastar con documentos coetáneos, a veces con silencios, otras alargando la pluma o, sin mentir, no ser tan fiel su relato como pretendió. Los méritos alegados en las dos probanzas conocidas sugieren una participación menos activa que lo contado con el paso del tiempo en la extensa probanza en que se convirtió su Historia «para que haya memorable memoria de mi persona y de los muchos y notables servicios que he hecho».

De lo que no cabe duda es que, aunque Bernal recurriese al tópico de no ser letrado, construyó un relato al que sus contemporáneos otorgaron autoridad por su condición de testigo. Le acompañaba la fama de «Bernal Díaz, "el conquistador"». Memoria, deseo y olvido tejieron un relato en el que se ha investigado más su reconocido valor literario que su fiabilidad histórica.

\section{BIBLIOGRAFÍA}

Adorno, Rolena, "Hystory, Law, and the Eyewitness: Protocols of Authority in Bernal Díaz del Castillo's Historia verdadera de la conquista de la Nueva España", Elizabeth Fowler and Roland Greene (eds.), The Project of Prose in Early Modern Europe and the New World, Cambridge, Cambridge UP, 1997: 154-175.

Añón, Valeria, "Realismo, detalle y experiencia: acerca de la Historia verdadera de Bernal Díaz del Castillo", Latinoamérica. Revista de Estudios Latinoamericanos, 57 (México, 2013a): 213-245.

Añón, Valeria, "Memoria, proliferación y fama en la Historia verdadera de la conquista de la Nueva España", Zama, 5 (Buenos Aires, 2013b): 121-134.

Barbón Rodríguez, José Antonio, "Historia verdadera de la conquista de la Nueva España. Estudio", Bernal Díaz del Castillo, Historia verdadera de la conquista de Nueva España, México D.F./Madrid, El Colegio de México, Universidad Nacional Autónoma de México, Servicio Alemán de Intercambio Académico/Agencia Española de Cooperación Internacional, 2005: 3-1089.

Beckjord, Sarah H., Territories of History: Humanism, Rhetoric, and the Historical Imagination in the Early Chronicles of Spanish America, University Park, Pennsylvania, Pennsylvania State University Press, 2007.

Bernand, Carmen, Carrière, Jeanne-Monique, Gilbert, Claude, Naboulet, Mariette, Sakowicz, Krzyszstof et Thomas, Laurent, "Machiavel ou Rocambole? Quelques 
réflexions collectives à propos de Christian Duverger, Cortés et son double. Enquête sur une mystification, Paris, Seuil, 2013", Nuevo Mundo Mundos Nuevos [en ligne], Comptes rendus et essais historiographiques, mis en ligne le 14 octobre 2013, consulté le 06 mai 2015, URL: http://nuevomundo.revues.org/65938.

Bravo Lozano, Jesús e Hidalgo Nuchera, Patricio, De indianos y notarios, Madrid, Consejo General del Notariado, 1995.

Cerwin, Herbert, Bernal Díaz, Historian of the Conquest, Norman, University of Oklahoma press, 1963.

Cortés, Vicenta, "Cuándo murió Bernal Díaz del Castillo", Boletín Americanista, 1018 (Barcelona, 1962): 23-25.

Cortínez, Verónica, Memoria original de Bernal Díaz del Castillo, México, D.F., Oak, 2000.

Cunnighan Graham, Robert Bontine, Bernal Díaz del Castillo, historiador de la conquista. Semblanza de su personalidad a través de su Historia verdadera de la conquista de la Nueva España, Buenos Aires, Editora Inter-americana, 1943.

Díaz del Castillo, Bernal, Historia verdadera de la conquista de la Nueva España escrita por el Capitan Bernal Diaz del Castillo uno de sus conquistadores. Sacada a luz por el P. M. Fr. Alonso Remon, Predicador, y Coronista General de la Orden de Nuestra Señora de la Merced Redempcion de Cautivos. A la Catholica Magestad del mayor Monarca Don Felipe Quarto, Rey de las España y Nuevo Mundo, N. Señor. Con privilegio, en Madrid, en la Imprenta del Reyno, 1632.

Díaz del Castillo, Bernal, Historia verdadera de la conquista de la Nueva España: Manuscrito Guatemala. Edición crítica de José Antonio Barbón Rodríguez, México D.F./Madrid, El Colegio de México, Universidad Nacional Autónoma de México, Servicio Alemán de Intercambio Académico/Agencia Española de Cooperación Internacional, 2005.

Duverger, Christian, Crónica de la eternidad ¿Quién escribió la Historia verdadera de la Conquista de la Nueva España?, México, Taurus, 2012.

“El misterioso Bernal Díaz”, Nexos, 424 (México, 2013): 40-69. También en Nexosenlinea, puesto en línea el 1 de abril de 2013, URL: http://www.nexos.com. $\mathrm{mx} / \mathrm{p}=15251$ [consulta 5 de abril de 2013].

Gil, Juan, "Prólogo", Bernal Díaz del Castillo, Historia verdadera de la conquista de la Nueva España, Madrid, Fundación José Antonio de Castro, 2012: XXXI-LXXXIX.

Graulich, Michel, “«La mera verdad resiste a mi rudeza»: Forgeries et mensonges dans l'Historia verdadera de la conquista de la Nueva España de Bernal Díaz del Castillo", Journal de la Société des Américanistes, 82 (Paris, 1996): 63-95.

Grunberg, Bernard, Dictionnaire des conquistadores de Mexico, Paris, L'Harmattan, 2001. 
León Pinelo, Antonio de, Epitome de la Biblioteca Oriental i Occidental, Nautica i Geografica. Al excelentísimo..., En Madrid, por Iuan Gonzalez, 1629.

León-Portilla, Miguel, "Ramírez de Fuenleal y las antigüedades mexicanas", Estudios de cultura Náhuatl, 8 (México, 1969): 9-49.

López de Gómara, Francisco, La Istoria de las Indias y conquista de México, Zaragoza, en casa de Agustín Millán, 1552.

Martínez Baracs, Rodrigo, "El primer documento conocido escrito en México por los conquistadores españoles", Historias, 60 (México, enero-abril 2005): 113-123.

Martínez Baracs, Rodrigo, "Bernal o Cortés”, Letras Libres (México, junio 2013): 28-30.

Martínez Martínez, María del Carmen, Veracruz 1519. Los hombres de Cortés, León, Universidad de León, Secretariado de Publicaciones/Conaculta-Instituto Nacional de Antropología e Historia, 2013.

Martínez Martínez, María del Carmen, "Hernán Cortés en España (1540-1547): negocios, pleitos y familia", Martín Ríos Saloma (ed.), El mundo de los conquistadores, Madrid-México, Sílex-Universidad Nacional Autónoma de México, 2015: 577-598.

Miralles, Juan, Y Bernal mintió. El lado oscuro de su Historia verdadera de la conquista de la Nueva España, México D.F., Taurus, 2008.

Mund, Sabine, Les rapports complexes de l'Historia verdadera de Bernal Díaz avec la vérité, Bruxelles, Koninklijke Akademie voor Overzeese Wetenschappen, 2001.

Pinto Soria, Julio César, "Bernal Díaz del Castillo en Guatemala", Iberoamericana, XIV/55 (Berlín, 2014): 9-28.

Reynolds, Winston A., El corregidor Diego Díaz del Castillo (hijo del conquistador) ante la Inquisición de México (1568-1571), Madrid, José Porrúa Turanzas, 1973.

Sáenz de Santa María, Carmelo, "Un documento inédito sobre Bernal Díaz del Castillo: la probanza de su nieto, don Tomás Díaz del Castillo", Revista de Indias, 21 (Madrid, 1961): 159-182.

Sáenz de Santa María, Carmelo, Historia de una Historia. Bernal Díaz del Castillo, Madrid, CSIC, Instituto Gonzalo Fernández de Oviedo, 1984.

Serés, Guillermo, "Estudio y Anexos", Bernal Díaz del Castillo, Historia verdadera de la conquista de la Nueva España, Madrid, Real Academia Española, 2011: 116-1142.

Serés, Guillermo, "Sobre la disputada autoría de la Historia verdadera de la conquista de la Nueva España", Boletín de la Biblioteca de Menéndez Pelayo, LXXXIX (Santander, enero-diciembre 2013): 15-61.

Straub, Heberhard, Das Bellum justum des Hernán Cortés in Mexico, Köln/Wien, Böhlau Verlag, 1976. 
Thomas, Hugh, "Una nueva Historia de una conquista vieja", Letras Libres (México, junio 2013): 31-33.

Torquemada, Juan de, Monarquía indiana, Introducción de Miguel León Portilla, México, Porrúa, 1969.

Wagner, Henry R., "Bernal Díaz del Castillo. Three studies on the same subjet", The Hispanic American Historical Review, 25 (Washington, 1945): 155-211.

Fecha de recepción: 9 de octubre de 2015.

Fecha de aceptación: 24 de noviembre de 2015.

\section{Bernal Díaz del Castillo: memory, invention and omission}

This article refers to previously unpublished documents to demonstrate Bernal Diaz de Castillo's writing skills and role as escribano, to shed light on the open debate surrounding this historical figure. These documents include: testimonies by his contemporaries that accredit him with authorship of Historia Verdadera; the lawsuit of fiscal Villalobos, in which three of the Conquistador's petitions are conserved; and Probanza ad Perpetuam Rei Memoriam, written in the town of Espiritu Santo in March, 1539, in which there is no mention of his participation in the expedition of Grijalva.

Key words: Bernal Díaz del Castillo; New Spain; Guatemala; sixteenth century; Chroniclers; Conquistadors. 